\title{
PRÁTICAS PEDAGÓGICAS E INCLUSÃO: A SOBREVIVÊNCIA DA INTEGRAÇÃO NOS PROCESSOS INCLUSIVOS
}

\author{
Hildete PEREIRA dos ANjos* \\ LUCIANA BARBOSA DE MELO** \\ KÁTIA REgINA DA SILVA* ${ }^{* * *}$ \\ LUCÉLIA C. CAVALCANTE RABELO ${ }^{* * * *}$ \\ MARCELo AlMEIDA ARAÚJo $0^{* * * *}$
}

\begin{abstract}
RESUMO: O trabalho apresenta uma análise do processo inclusivo, retomando os conceitos de prática pedagógica e inclusão. Com instrumentais da análise de discurso e da análise de conteúdo, analisa entrevistas com professores de atendimento especializado, professores de sala comum e gestores. Descreve inclusão como um conceito cuja rede de sentidos oscila conforme os interesses em jogo, sendo tanto processo que envolve vários agentes e instâncias e exige participação, quanto idealização, definida a priori e devendo ser incorporada de forma acrítica. Aponta o desconhecimento das especificidades de aprendizagem e dos potenciais dos sujeitos e grupos; a sobrevivência do modelo clínico; os estudos da inclusão como apêndice do processo formativo; certas iniciativas com caráter mais integrativo do que inclusivo. Propõe investir na escola concreta, através de modelos de pesquisa interventivo-participativo, e refazer de outro ângulo as questões já formatadas sobre prática pedagógica inclusiva.
\end{abstract}

Palavras-chave: Deficiência. Inclusão. Prática pedagógica.

\footnotetext{
* Doutora em Educação e professora do Programa de Pós-Graduação em Dinâmicas Territoriais e Sociedade na Amazônia, da Universidade Federal do Pará (Ufpa). E-mail: hpanjoma@ufpa.br

** Especialista em Psicologia Educacional e técnica em Educação da Secretaria Estadual de Educação de Marabá (PA). E-mail: lb_melo@hotmail.com

*** Mestre em Educação e professora da Universidade Federal do Pará (Ufpa).E-mail: katiars@ufpa.br

**** Doutoranda no Programa de Pós-Graduação em Educação Especial da Universidade Federal de São Carlos (Ufscar) e Técnica Pedagógica da Universidade Federal do Pará (Ufpa).

E-mail: lucelia@ufpa.br

***** Especialista em Educação da Secretaria de Estado da Educação (Marabá, PA) e professor substituto da Universidade Federal do Pará (Ufpa).E-mail: marceloaa@ufpa.br
} 


\title{
Pedagogical practices ANd inClusion:
}

\section{THE SURVIVAL OF INTEGRATION IN INCLUSIVE PROCESSES}

\begin{abstract}
This work presents an analysis of the inclusive process, revisiting the concepts of pedagogical practice and inclusion. With instruments from the fields of content analysis and discourse analysis, it analyses interviews with specialized care teachers, teachers in mainstream classrooms and managers. It describes inclusion as a concept whose network of meanings varies according to the interests involved, being conceived as a process that involves multiple agents and agencies and requires participation and as idealization, being defined a priori and to be incorporated uncritically. It points to the lack of knowledge of the specificities of learning and the potential of individuals and groups; the survival of the clinical model; the inclusion studies as an appendix of the training process; certain initiatives with more integrative than inclusive character. It intends to focus on the real school, through intervention and participatory research and to redo, from another angle, the issues already formatted on inclusive pedagogical practice.
\end{abstract}

Key words: Disability. Inclusion. Pedagogical practice.

\section{Pratiques pédAgogiques ET INCLUSION:}

\section{LA SURVIE DE L'INTÉGRATION DANS LES PROCESSUS INCLUSIFS}

RÉSUMÉ: Le travail présente une analyse du processus inclusif, en reprenant les concepts de pratique pédagogique et l'inclusion. Avec des instrumentaux de l'analyse de discours et de l'analyse de contenu, il analyse des entretiens avec des enseignants de service spécialisé, des enseignants de salle de classe et des directeurs d'écoles. Il décrit l'inclusion comme un concept dont le réseau de sens oscille d'après les intérêts en jeu, en étant de telle façon processus qui implique plusieurs agents et instances et exige de la participation, si bien l'idéalisation, définie à priori et devrait être incorporée de forme acritique. Il indique l'ignorance des spécificités d'apprentissage et des potentiels des sujets et des groupes; la survie du modèle clinique; les études de l'inclusion comme annexe du processus formatif; certaines initiatives avec caractère plus intégratif qu'inclusif. Il propose d'investir dans l'école concrète, à travers les modèles de recherche interventif-participatif, et de proposer sur un autre angle les questions déjà formatées sur pratique pédagogique inclusive.

Mots-clés: Handicap scolaire. Inclusion. Pratique pédagogique.

\section{Introdução}

7 ratar das práticas inclusivas na escola tem sido recorrente entre os pesquisadores, tendo já permeado as discussões sobre as distinções entre segre1 gação, integração e inclusão (SASSAKI, 1997; STAINBACK; STAINBACK; 1999; SKLIAR, 2001; FERREIRA, 2004; MANTOAN, 2004; OMOTE, 2004), sobre o histórico da educação especial (MAZZOTA, 2003; JANUZZI, 2006), sobre políticas sociais e inclusão (KASSAR, 1998; LAPLANE; GÓES, 2004; SILVA; VIZIM, 2001), 
entre outros. Mais recentemente, no entanto, o foco se voltou com mais atenção sobre o fazer pedagógico em sala de aula, portanto, sobre o professor e sobre as técnicas e métodos que podem tornar uma ação pedagógica inclusiva. Mendes (2006, p. 402), em trabalho que analisa o debate sobre inclusão escolar no Brasil, chama a atenção para a necessidade de trazer a prática pedagógica para o foco da pesquisa:

Entretanto, só o acesso não é suficiente, e traduzir a filosofia de inclusão das leis, dos planos e das intenções para a realidade dos sistemas e das escolas requer conhecimento e prática. É preciso, portanto, questionar: Qual a prática necessária? E o conhecimento necessário para fundamentar a prática? E este é, sem dúvida nenhuma, um exercício para a pesquisa científica.

Pode ser tentador, nesses tempos em que o "saber fazer" retoma um lugar privilegiado nas análises educacionais, apontar as falhas nos fazeres existentes e sugerir novas competências, baseadas em princípios também definidos a priori. Para falar de práticas inclusivas nas escolas, no entanto, cremos que é necessário retomar as discussões a respeito do significado das noções de prática pedagógica e de inclusão. Neste texto, tomamos essa discussão como base para apresentar um processo de pesquisa que, durante os anos de 2007 a 2009, enfocou as ações pedagógicas e as políticas públicas relativas à inclusão num município da região Norte do país.

Anteriormente, já criticávamos a tendência a descolar o "fazer" educação especial e o "pensar" essa mesma educação. Estudando os discursos (oficial, acadêmico e escolar ${ }^{1}$ ) acerca da inclusão, percebíamos neles uma cisão entre prática e discurso: elegiam-se determinadas instâncias como produtoras de discurso válido e outras como simples consumidoras desse discurso. No polo entendido como da prática (o fazer docente) não se imaginava a possibilidade de pensar e refazer essa mesma prática, atribuindo a processos formativos externos essa função. Criticávamos, especificamente, a tendência a recusar a escola realmente existente - e seus modos de dizer, pensar e fazer a inclusão - como matéria-prima para uma reconstrução de conceitos e práticas.

Ali, a noção de inclusão aparecia como um conceito em construção (incorporando-se aqui a noção de que as palavras se desenvolvem, como descrito em Vigotski [1998]): tanto podia significar a mudança necessária nos sistemas educacionais para incorporar a diferença, aparecendo como processo conflituoso, quanto podia se desenhar como uma idealização a ser alcançada, cujos contornos já estariam pré-definidos. Oscilava entre um e outro significado, conforme os interesses em jogo. Tais conclusões geraram nova pesquisa (2007) cuja intenção era continuar analisando, nos processos inclusivos, os modos como o professor via a si mesmo e a outros agentes nessa dissociação entre pensar e fazer.

Estudando as práticas inclusivas a partir das falas dos professores, observamos que dois mundos eram desenhados: um no qual o professor se descrevia como 
tendo papel determinante - a sala de aula - e outro externo a ele, distanciado, no qual apareciam os processos excludentes. No que se referia à sala de aula, ele assumia para si todas as dificuldades e dilemas do processo inclusivo, colocando em segundo plano limitações históricas da educação brasileira, como classes superlotadas, baixos salários, formação deficiente, entre outras.

Reforçava-se a concepção de inclusão como idealização e não como processo. A exclusão se desenhava como imposição externa, pela qual o falante não teria responsabilidades. Este também não se descrevia como excluído, ou como passível de inclusão. Nessa concepção de inclusão como idealização, a problematização criada pela presença de alunos antes segregados aparecia como uma situação contrária à inclusão, e não como parte do próprio processo inclusivo, como evidenciava Oliveira (2007), destacando o processo de tornar visíveis os alunos em situação de deficiência.

Por fim, as relações discursivas estabelecidas com outros interlocutores mostravam também dois polos: distantes, fora do alcance da ação do professor, eram citados o sistema e o governo, os quais decidiam por ações inclusivas ou excludentes; próximos, apareciam os professores do atendimento especializado - descritos como os responsáveis pela criança em situação de deficiência - e os alunos, geralmente idealizados ou como modelo de bom comportamento, de empenho e esforço, ou como impossibilitados de avançar devido à deficiência.

\section{Do percurso metodológico}

Nas pesquisas iniciais, o percurso metodológico propriamente dito se inspirou na análise de discurso (ORLANDI, 2005; VERÓN, 1980; PECHEUX, 2006; FOUCAULT, 2006), buscando inicialmente distinguir as principais temáticas presentes no discurso e, depois, analisando os modos de operar com tais temáticas, configurar formações discursivas dominantes e recessivas (entendendo recessivas como formações que, embora dominadas, permanecem à espera de uma brecha discursiva para ganharem força e emergirem). No último ano, como a pesquisa se ampliou e passou a fazer parte de uma rede de pesquisa em educação inclusiva, a metodologia foi modificada e passou a se basear na análise de conteúdo (BARDIN, 1979), para a pesquisa geral, ficando os pesquisadores livres para proceder a outras análises com metodologias específicas, o que pretendemos efetivar retornando à análise de discurso.

\section{Inclusão no Brasil: aportes teóricos}

Para essa análise dos processos inclusivos com foco na prática pedagógica, partimos de um histórico da experiência brasileira, considerando, com Mendes 
(2006), que ela se inspirou em modelos de inclusão de outros países e não levou em conta, conforme Beyer, as condições concretas das escolas brasileiras:

\begin{abstract}
A particularidade da experiência brasileira da integração ou inclusão escolar reside no fato de que sua história não se assentou sobre a iniciativa de pais, familiares e escolas, porém foi articulada por estudiosos da área e técnicos de secretarias. Em vez de se constituir num movimento gradativo de decisões conjuntas entre pais e educadores, com imediata reversão em ações de implementação e adaptação das escolas e dos professores na direção do projeto inclusivo, ocorreu um movimento deslocado da base para o topo. Assim, quando as diretrizes político-pedagógicas da educação inclusiva foram definidas, muito pouco de história concreta nas escolas, entre as famílias e educadores, no sentido de ações efetivas de integração ou inclusão escolar, Brasil afora, havia sido feito. (BEYER, 2005, p. 8)
\end{abstract}

Sem essa história pedagógica da integração e da inclusão, na qual as experiências educacionais pudessem gerar concepções e princípios inclusivos, os princípios do modelo clinico-médico assumiram proeminência nesse processo. Tal abordagem, afirma Beyer (2007, p. 75), “acentua as características deficitárias da pessoa com necessidades especiais, ou seja, a partir do modelo médico de saúde e funcionalidade orgânica, são destacados os elementos patogênicos. A valorização da pessoa como tal fica prejudicada".

Essa sobrevivência do modelo médico (mesmo nos processos inclusivos mais recentes), quando relacionada com a adaptação curricular, organiza as práticas pedagógicas no sentido da adequação metodológica às categorias de deficiência, e não aos potenciais criados pela interação entre diferentes:

O termo adaptação curricular, relacionado ao modelo médico-psicológico de organizar as atividades educacionais aos diagnósticos e prognósticos clínicos sobre o desenvolvimento dos sujeitos, continua presente nas proposições políticas. A adaptação curricular ganhou historicamente, no campo da educação especial, o sentido de adequar métodos, técnicas e recursos aos diferentes diagnósticos dos alunos, a partir das categorias de deficiência: surdo, cego, deficiente físico, mental, múltiplo; das condutas típicas e das altas habilidades. (GARCIA, 2007, p. 15)

Superar a hegemonia do modelo clínico, assim como a ontologização da limitação dele decorrente e as adaptações curriculares que se conformam a esse modelo, exigiria mudanças nas noções de deficiência, de inclusão e de aprendizagem.

Uma mudança na noção de deficiência que, em nossa opinião, serve a essa superação, vem da contribuição de Diniz (2007), a qual, a partir das noções defendidas pela Upias, ${ }^{2}$ desvincula lesão de deficiência, situando aquela no corpo e esta na sociedade, sendo que a deficiência é gerada e fortalecida por barreiras dos mais variados tipos: físicas, corporais, atitudinais e culturais. Consideramos complementar a essa concepção a noção de estigma, conforme defendido em Goffman (2008, 
p. 13), como "um tipo especial de relação entre atributo e estereótipo", o qual cria uma situação em que o sujeito é, a priori, desacreditado, desacreditável ou ambas as opções. Desse modo, faz-se necessário entender os processos de desacreditação do sujeito como elaboração cultural e distingui-los da existência real da lesão, para poder intervir pedagogicamente na produção de uma cultura da diversidade.

A inclusão, desse ponto de vista, precisa evidenciar os problemas criados pelos processos excludentes, e não acobertá-los. Precisa desvendar processos de estigmatização, de produção de situações de deficiência, evidenciar mecanismos de produção discursiva que reforçam o preconceito e as tentativas de homogeneização dos sujeitos, definindo-os pela sua lesão. Diz Oliveira (2007, p. 39) que tais sujeitos "de invisíveis passaram e ser visíveis, de não problema passaram a ser problema, evidenciando não a inclusão, mas a passagem, a transição qualitativa de um estado de negação a um estado de problematização". Quer nos parecer que esse estado de problematização já poderia ser considerado parte do processo inclusivo, porque, ao considerar a existência desses sujeitos e seu pertencimento aos espaços escolares, já pressupõe a necessidade do estabelecimento de processos coletivos de aprendizagem entre diferentes.

Considerando então a cultura como locus de produção da deficiência e a inclusão como processo transitivo, que não pode deixar de considerar a história da educação especial, nossa concepção de aprendizagem precisará levar em conta as interações. O aprender necessita ser visto como um processo coletivo, interativo, intersubjetivo, como nos ensina Vigotski (1998): internalizar pressupõe incorporar, no jeito próprio de aprender, o jeito de aprender do outro.

Resumindo, então: a análise das práticas pedagógicas inclusivas, do ponto de vista deste trabalho, precisa: a) levar em conta a história da educação no Brasil e as condições concretas de nossas escolas; b) questionar os princípios do modelo clínico, ainda dominantes, deslocando o foco do indivíduo e sua lesão para os processos sociais de produção e reprodução da estigmatização e, portanto, da deficiência; c) levar em conta, portanto, que o aprender é um processo que tem origem nas relações entre as pessoas, mediadas por sua cultura, e que esta pode ser permanentemente reconfigurada.

\section{Acompanhando o fazer docente a partir das falas dos envolvidos}

Os resultados anteriormente descritos nos convenceram da necessidade de ampliar nossa compreensão do contexto no qual as falas estudadas faziam sentido e, ainda em 2008, envolvemo-nos numa pesquisa de maior porte. Esta tinha o objetivo de ampliar nossa compreensão do processo, enfocando a organização do sistema 
municipal de ensino, e, vinculada a esta, a política de educação inclusiva, enfatizando as diretrizes educacionais, a política de atendimento e a organização pedagógica escolar. Nesse caso, as definições gerais do projeto previam realizar uma análise dos conteúdos presentes nas falas de gestores municipais, diretores, coordenadores pedagógicos e professores de escolas, nas quais o processo inclusivo acontecia há mais tempo. ${ }^{3}$

Nesse trabalho, percebemos que os esforços de materialização de políticas inclusivas apareciam na melhoria de indicadores, no estabelecimento do atendimento educacional especializado, na criação de uma estrutura física mínima e na reprodução da programação federal de formação de professores para a educação inclusiva. Essa formação, ainda que padronizada, vinha de encontro às angústias do professorado, expressas na fala de Olga ${ }^{4}$ :

[...] todo mundo né..., demonstra interesse, querendo participar mais, porque sentem assim angustiados, é... de não fazer um bom trabalho, de não ter um retorno positivo no final do ano, a preocupação com esses alunos, se vai aprender, se não vai, se vai estar realmente inserido no processo de ensino aprendizagem, essa é a angustia de todos. (Olga, PB)

A padronização da formação é uma das contradições de uma rede excludente de relações, as quais se expressavam também na ausência de controle do processo de retenção/aprovação e no desconhecimento dos processos específicos de aprendizagem. Aquela ausência nos parecia um indício do mal-estar causado pela inadequação dos modelos vigentes de avaliação. Parecia evidente que tais modelos não serviam para os alunos em situação de deficiência, mas essa constatação não avançava para uma crítica dos modelos em si. A conclusão óbvia então é que o problema se situava fora do modelo: era colocado nos próprios alunos, em suas limitações, ou no professor, em seu despreparo.

Por outro lado, evidenciou-se uma crença ingênua de que manter o aluno numa sequência formal de séries criaria nele a ilusão de progressão. Tal crença oculta o fato de que qualquer criança percebe quando fracassa, mesmo que seja encaminhada para a série seguinte; de que tem a compreensão de que as turmas de aceleração aceleram o tempo de permanência na escola, mas não necessariamente sua compreensão dos conceitos.

O desconhecimento dos processos específicos de aprendizagem construídos por esses alunos, na relação com os modos tradicionais de ensinar, fazia com que as práticas fossem repetitivas, na expectativa de que as diferenças entre os alunos fossem questão apenas de ritmo e de tempo. Percebemos que, embora importante, o reconhecimento das diferenças não bastava, sendo necessário o conhecimento das especificidades, para a promoção da aprendizagem. Conhecer a especificidade, em 
nossa compreensão, não se traduz em conhecer como aprende um cego, um surdo, por exemplo, mas como, em determinadas circunstâncias, usando determinadas ferramentas, a partir de determinadas crenças e limitações, pondo em ação determinados potenciais e na interação com determinado grupo, uma pessoa aprende. Isso implica superar a individualização e a padronização da formação, as quais limitam a experimentação e impedem a valorização de experiências locais, singulares, diversas.

Os achados específicos acerca da prática inclusiva apontavam para uma supervalorização da adaptação curricular e de material, mas sem questionar o currículo em sua materialidade; ele continuava sendo o mesmo, cada vez mais uniforme, apesar da diversificação de atividades. Lembrando Garcia (2007, p. 17), essa supervalorização se vincula ao modelo médico-psicológico, o qual

[...] contribuiu para que a tarefa da educação especial estivesse a serviço de um sistema educacional de organização seriada, elitista e classificatória, produtor de exclusão da escola de ensino fundamental e estruturado historicamente por meio de uma organização racional do trabalho pedagógico com base na homogeneidade.

Como não havia mudanças concretas na estrutura escolar propriamente dita, as mudanças se limitavam a apresentar as mesmas coisas de forma diferente, com novos materiais, em tempo mais longo ou em ritmo mais vagaroso. Essa tarefa terminava cabendo ao professor, que se queixava, com razão:

[...] a dificuldade que eu sinto é em trabalhar na questão com as atividades diversificadas, né... porque o sistema lá não manda não dá nenhum subsídio pra gente ta trabalhando tipo assim: joga o aluno ali e você se vira, né... essa que é a realidade a gente tem que... né... o professor tem que ser tudo né... psicólogo... o médico... entendeu? Tem que fazer de tudo pra que esse aluno no final do ano ele tenha um rendimento né... tenha conhecimento... (Aldo, PA)

Garcia (2007) atribui a tendência a concentrar as modificações na escola nas adaptações curriculares a uma sobrevivência dos moldes consagrados pelo modelo clínico, e isso pôde ser entrevisto nas conclusões do professor citadas anteriormente: parecia-lhe que, para obter rendimento do aluno, seriam necessárias competências de médico e de psicólogo. Aparentemente, a presença de pessoas com certas especificidades no interior da escola pedia novos materiais e modos diferentes de apresentar os conteúdos, mas não os questionava. Sobreviviam, então, a distribuição e fragmentação de tarefas, cabendo as adaptações e a responsabilidade pelo aluno em situação de deficiência ao professor de atendimento especializado, que geralmente era o antigo professor de educação especial.

Olha aqui na escola... foi a escola pioneira nesse plano, tem a sala de recursos, tem professores... os professores... o atendimento especializado no contraturno... Bem atuante a professora, pergunta se a gente tem dificuldades de trabalhar com alunos de DA, no 
caso a ajuda é somente com os DA's praticamente, as outras áreas com deficiência, não tem essa capacitação, eu nunca participei. (Olga, PB)

Esse aluno ainda era tido como "alheio", pertencente a uma dimensão estranha, ainda que partilhando o mesmo território. Esse alheamento transparece na fala da professora Luiza, quando se refere à sala multifuncional como sendo "a sala deles lá, a sala especial":

Porque eles já vêm pra sala deles lá, sala especial, eles vêm. Então às vezes eles vão pra lá, mas às vezes eles acham que não tem necessidade de vir pra minha sala, mas quando eles vêm eu tenho que ter um atendimento direcionado pra eles. Como eu tenho mais alunos que não precisam de atendimento naquela hora, aí existe aquela confusão né, aquele barulho, às vezes a aluno lá que não tem nada a ver vem, requer a minha atenção, eu tenho que deixar o meu aluninho aqui pra ir lá pra salas deles, essa é a dificuldade que eu encontro. (Luiza, PB)

As conclusões provisórias, até então, mostravam que aquilo que chamávamos de processo inclusivo poderia ser entendido mais como a busca de atender às disposições de um processo integrativo, se fôssemos nos ater aos rótulos de praxe. Se levarmos em conta a história da inclusão em terras brasileiras (BEYER, 2005), no entanto, veremos que não devem ser estabelecidas fronteiras interpretativas baseadas nesses rótulos. Avaliar o processo inclusivo, levando em conta apenas as distinções já estabelecidas entre integração e inclusão e as críticas à integração presentes na literatura, ignorando as condições concretas da experiência localizada, pode ser extremamente danoso aos esforços de superação das limitações educacionais locais, reduzindo o valor dos avanços reais. A fala da gestora mostra a percepção de que o plano municipal de educação poderia ter ido além no que se refere à inclusão, mas que haviam questões que extrapolavam a questão da deficiência:

\footnotetext{
Entendemos que o plano poderia ter avançado mais no sentido de que a filosofia de educação inclusiva perpasse todas as ações. Contudo, quando se pensa e se propõe diretrizes para construção de uma educação de qualidade para todos, isso é educação inclusiva. No plano também estão garantidos os Atendimentos Educacionais Especializados, AEE, e ações de parceria com demais órgãos que zelam pelo direito do indivíduo com deficiência. (Laura, CEE)
}

Concluímos, provisoriamente, que o conceito de inclusão continua em disputa e em elaboração. Em suas redes de sentidos se imbricam os enfrentamentos que são, ao fim e ao cabo, os mesmos da educação como um todo: uniformização, fragmentação e imobilidade curricular; fragmentação de tarefas entre sujeitos, atribuindo a uns a função de pensar e a outros a função de fazer; imposição de projetos externos, baseada na crença de que não é possível produzir propostas adequadas a partir da escola concreta; idealização do aluno, do professor, da escola e de seus processos; individualização do atendimento e do acesso ao conhecimento, entre muitos outros. 


\section{Considerações iniciais para uma prática inclusiva}

Para além das conclusões, consideramos importante tecer algumas considerações, fruto de nosso esforço de pesquisa até aqui e do nosso envolvimento com as ações concretas do processo de inclusão. Enfocamos aqui aspectos que consideramos mais importantes neste momento: a superação da dicotomia entre o fazer e o pensar pedagógicos, diluição das fronteiras entre sujeitos e grupos, a retomada da noção de diferença (assumindo que ela incorporou os sentidos da noção de "especial"), a análise das situações socioculturais de deficiência e, finalmente, a reformulação das questões que estão na base da prática pedagógica inclusiva.

Para superar a dicotomia entre o fazer e o pensar, é necessário articular tais instâncias do humano a partir de projetos de inclusão reais e contextualizados, utilizando a literatura inclusiva como ferramenta e não como receita. Isso permitirá questionar o habitus (BOURDIEU, 1994), considerando cada instância do fazer como instância de produção do pensar; permitirá ainda, observando o modo de funcionamento de tais instâncias, explicitar o distanciamento entre as análises da exclusão e da inclusão, retomando-os como conceitos interconstituintes. Desse ponto de vista, pesquisas de modelo interventivo-participativo, envolvendo todos os sujeitos da escola, podem ser muito mais produtivas do que o modelo tradicional de levantamento de dados.

Também há necessidade de diluir as fronteiras entre os sujeitos e grupos, que recortam e fragmentam as práticas pedagógicas. Tais fronteiras transparecem nos enfrentamentos entre o pessoal do atendimento educacional especializado e o professor de sala comum; no debate sobre de quem é o aluno "especial", quem é responsável pelo seu sucesso; no "especial" entendido como uma temática-apêndice na formação de professores e não como transversalidade; enquanto atividade, entendida como responsabilidade de uma equipe específica e não de todo o corpo docente. A diluição dessas fronteiras passa, necessariamente, pelo reconhecimento de sua existência e pelo estudo de como elas se forjaram, passa pela retomada dos estudos acerca da história e dos fundamentos filosóficos da educação especial.

Superar essas fronteiras implica também diluir a noção de "especial", assumindo que ela continua sendo um conceito base para o de inclusão. Não basta substituir tal conceito pela noção de diferença, imaginando que ele assim desaparece. Ele persiste como noção recessiva, e é forte o suficiente para incorporar sua rede de sentidos ao novo conceito. Enquanto o aluno incluso continuar tendo a deficiência (o "especial") como definidora de sua identidade, sua diferença será de segunda categoria. Não serão pensadas situações, instrumentos, mecanismos e circunstâncias que propiciem o aprender como um processo coletivo, interativo, intersubjetivo (VIGOTSKI, 1998), porque não serão considerados seus potenciais para contribuir nesse processo. Sobreviverá o modelo médico, travestido de social (de novo, uma 
noção recessiva se impondo como geradora de sentido para palavras e expressões oriundas ou vinculadas ao modelo social).

Parece importante, ainda, evidenciar as situações de deficiência no grupo e na sociedade, observando e combatendo as barreiras que geram e fortalecem a deficiência (DINIZ, 2007). Reagir a essa ontologização da limitação $0^{5}$ pressupõe ampliar as fronteiras definidoras dos sujeitos, percebendo em sua constituição o processo de interconstituição próprio dos seres humanos, sociais que somos por definição. Não organizaremos nossas ações a partir de uma previsão baseada numa noção de identidade fixa, mas sim como construção cultural e, portanto, dinâmica, passível de superação. Como bem nos lembra Silva (2006, p. 427), "o estigma, por ser uma marca, um rótulo, é o que mais evidencia, possibilitando a identificação. Quando passamos a reconhecer alguém pelo rótulo, o relacionamento passa a ser com este, não com o indivíduo".

Por fim, consideramos necessário refazer de outro ângulo as perguntas clássicas que se costuma fazer na elaboração de práticas pedagógicas: "como incluir pessoas com deficiência?"; "quais são as técnicas, qual é o método?". Nós nos perguntamos outras coisas: como reduzir os processos excludentes? Como forjar novas formas de ver a deficiência, evidenciando sua origem sociocultural? Que métodos podem ser elaborados e reelaborados, na interação com os modos de ver o mundo desses sujeitos? Perguntamo-nos como nos incluir em suas lutas por educação, por informação, por acesso aos direitos mais básicos. Acreditamos que tal inversão pode contribuir na redução das desigualdades, reconhecendo nesse outro um sujeito e não um mero objeto de nossa atuação. Não se trata de incluir os outros, promovendo a sua aprendizagem a partir de parâmetros adaptados da normalidade, mas de incluir-se numa relação aprendente. Há, portanto, um longo caminho a ser trilhado, e isso só pode ser feito de forma coletiva, envolvendo pesquisadores, comunidade escolar e instâncias governamentais.

\section{Notas}

1. Como suporte do "discurso oficial", foi analisada uma coletânea, editada pelo MEC, destinada à formação de professores para a inclusão; do "discurso acadêmico", uma série de recortes de artigos acadêmicos que definiam inclusão e do "discurso escolar", falas de professores envolvidos com o atendimento educacional especializado.

2. Upias: sigla em inglês da Liga dos Lesados Físicos contra a Segregação (DINIZ, 2007).

3. Foram entrevistados três diretoras e seis professores/as, de três escolas da rede pública que contam com sala multifuncional e participavam do processo de inclusão há mais de quatro anos, além de uma gestora municipal da educação especial.

4. Os nomes dos entrevistados foram substituídos por pseudônimos, para garantir o anonimato, e identificados com relação à sua atuação (por exemplo: PA - professora da escola A, CEE - coordenadora de educação especial, por exemplo). 
5. Fala-se "do deficiente", gerando-se um processo de generalização (ontologização) da limitação funcional. A limitação em determinada área perde seu caráter parcial e adquire uma conotação substantiva. Define-se o todo pela parte (BEYER, 2007).

\section{Referências}

BARDIN, L. Análise de conteúdo. Lisboa: Edições 70, 1979.

BEYER, H.O. Inclusão e avaliação na escola: de alunos com necessidades educacionais especiais. Porto Alegre: Mediação, 2005.

BEYER, H.O. O projeto da educação inclusiva: perspectiva e princípios de implementação. Porto Alegre: Mediação, 2007.

BOURDIEU, P. Esboço de uma teoria da prática. In: ORTIZ, R. (Org.). Pierre Bourdieu. São Paulo: Ática, 1994.

DINIZ, D. O que é deficiência. São Paulo: Brasiliense, 2007.

FERREIRA, J.R. Políticas públicas e universidade: uma avaliação dos dez anos da declaração de Salamanca. In: OMOTE, S. Inclusão: intenção e realidade. Marília: Fundepe, 2004.

FOUCAULT, M. A ordem do discurso. 13. ed. São Paulo: Loyola, 2006.

GARCIA, R.M.C. O conceito de flexibilidade curricular nas políticas públicas de inclusão educacional. Porto Alegre: Mediação, 2007.

GOFFMAN, E. Estigma: notas sobre a manipulação da identidade deteriorada. 4. ed. Rio de Janeiro: LTC, 2008.

JANNUZZI, G.M. A educação do deficiente no Brasil: dos primórdios ao início do século XXI. 2. ed. Campinas: Autores Associados, 2006.

KASSAR, M.C.M. Liberalismo, neoliberalismo e educação especial. Cadernos Cedes, Campinas, v. 19, n. 46, p. 16-28, set. 1998.

LAPLANE, A.L.F.; GÓES, M.C.R. Políticas e práticas de educação inclusiva. Campinas: Autores Associados, 2004.

MANTOAN, M.T.E. O direito de ser, sendo diferente, na escola. In: OMOTE, S. Inclusão: intenção e realidade. Marília: Fundepe, 2004.

MAZZOTA, M. Educação especial no Brasil: história e políticas públicas. São Paulo: Cortez, 2003.

MENDES, E.G. A radicalização do debate sobre inclusão escolar no Brasil. Revista Brasileira de Educação, Campinas, v. 11, n. 33, p. 387-405, set./dez. 2006. 
OLIVEIRA, I.A. Política de educação inclusiva nas escolas: trajetórias e conflitos. Porto Alegre: Mediação, 2007.

OMOTE, S. Inclusão: intenção e realidade. Marília: Fundepe, 2004.

ORLANDI, E.P. Análise de discurso: princípios e procedimentos. 5. ed. Campinas: Pontes, 2005.

PÊCHEUX, M. O discurso: estrutura ou acontecimento. 4. ed. Campinas: Pontes, 2006.

SASSAKI, R. Inclusão: construindo uma sociedade para todos. Rio de Janeiro: WVA, 1997.

SILVA, L.M. O estranhamento causado pela deficiência: preconceito e experiência. Revista Brasileira de Educação, Campinas, v. 11, n. 33, p. 424-434, set./dez. 2006.

SILVA, S.; VIZIM, M. (Org.). Educação especial: múltiplas leituras e significados. Campinas: Mercado das Letras; Associação de Leitura do Brasil, 2001.

SKLIAR, C. Perspectivas políticas e pedagógicas da educação bilíngüe para surdos. In: SILVA, S.; VIZIM, M. (Org.). Educação especial: múltiplas leituras e significados. Campinas: Mercado das Letras; Associação de Leitura do Brasil, 2001.

STAINBACK, S.; STAINBACK, W. Inclusão: um guia para educadores. Porto Alegre: Artes Médicas, 1999.

VERÓN, E. A produção de sentido. São Paulo: Cultrix; Edusp, 1980.

VIGOTSKI, L.S. A formação social da mente. São Paulo: Martins Fontes, 1998.

Recebido em 27 de julho de 2011.

Aprovado em 30 de julho de 2012. 